\title{
DIVERSITY ASSESSMENT OF FOXTAIL MILLET (Setaria italica L. Beauv) ACCESSIONS COLLECTED FROM DIFFERENT LOCATIONS OF NEPAL
}

\author{
Manoj Sapkota ${ }^{1 *}$, Madhav Prasad Pandey ${ }^{2}$, Dhruba Bahadur Thapa ${ }^{3}$, Mukesh Kumar Yadav ${ }^{1}$, Sapana Ghimire ${ }^{1}$ and \\ Dipak Timalsina ${ }^{1}$
}

\author{
${ }^{1}$ Institute of Agriculture and Animal Science, Tribhuvan University, Rampur, Chitwan, Nepal \\ ${ }^{2}$ Department of Genetics and Plant Breeding, Agriculture and Forestry University, Rampur Chitwan, Nepal \\ ${ }^{3}$ Agriculture and Botany Division, Nepal Agricultural Research Council, Lalitpur, Nepal \\ *Corresponding author email: manoj34sapkota@gmail.com
}

\begin{abstract}
Foxtail millet (Setaria italica L. Beauv) categorized as an underutilized crop in Nepal persist a large diversity among different germplasms and accessions found in the country. Ten foxtail millet accessions were collected from different parts of Nepal and were evaluated for assessing the diversity in different characters at Institute of Agriculture and Animal Science, Rampur, Chitwan. The accessions were experimented in Randomized Complete Block Design with three replications. Observations were taken for qualitative traits i.e. tip of first leaf, anthocyanin at leaf base, lobe compactness, length of bristles, anthocyanin presence, leaf blade altitude, flag leaf color, lobe in panicles, panicle lodging, inflorescence compactness, overall color, panicle anthocyanin, panicle shape and growth habit. Shannon Weiner index and Evenness were calculated to assess the diversity in the accessions under study. The maximum number of diversity in traits of lobe compactness of panicle (1.3624) followed by panicle lodging (1.1595), inflorescence compactness (1.1235) and length of bristles (1.0681). Least diversity was observed in trait of growth habit $(0.3926)$ followed by panicle anthocyanin coloration $(0.4505)$ and lobes in panicles $(0.5799)$. The finding of existence of wide diversity in the studied accessions could be a pivotal information for further study of genetic variation of foxtail millet germplasms.
\end{abstract}

Keywords: Foxtail millet; Setaria italica; Shannon Weiner index; Evenness; diversity

\section{Introduction}

Millet, considered as a major cereal crop of Nepal, is cultivated in an area of 271,183 ha with the production of 304,105 metric tons and productivity of $1,121 \mathrm{~kg} / \mathrm{ha}$ (MoAD, 2014). Foxtail millet (Setaria italica L. Beauv), a self-pollinating crop $(2 \mathrm{n}=18)$ is grouped under the family Poaceae and subfamily Panicoideae (Fedorov, 1974). It is cultivated in about 26 countries, and ranks second among the millets regarding world production. Around six million tons of foxtail millet is produced globally; mostly in the southern part of Europe, in tropical, sub-tropical and temperate Asia (Marathee, 1993). Millets were domesticated some 8000 years ago in the highlands of central China (Amgai et al., 2011). Foxtail millet is an important cereal since old times and has critical role in advancement of human civilization in Asia and Europe ( $\mathrm{Li}$ et al., 1996; Lu et al., 2009). Foxtail millet is a model crop that calls up international attention, which is the second most widely cultivated species of millet, mainly in East Asia. It comprises the oldest history of cultivation among the millets. (Lin et al., 2012). It is one of the type of millets comes under the category of underutilized and neglected crops in Nepal. It is small grain millet mainly cropped in the unirrigated and marginal water regime condition of mid and high hill areas of Nepal, mainly in the Karnali region of Nepal (HMGN/MFSC, 2002). Foxtail millet is hardy and has the potential to develop well in drought stressed conditions (Singh et al., 2015). Foxtail millet generally grown in semi-arid regions, has a low water requirement and can be considered as a second crop after wheat or barley, the major cereals. This is because of its short life cycle (Brink, 2006).

Nepal has high genetic diversity in foxtail millet (HMGN/MFSC, 2002). In Nepal, foxtail millets are grown up to the altitude of $3150 \mathrm{~m}$, resulting a diverse and large collection of the genotypes (Upreti, 1999). About 790 millet accessions have been identified from parts of Nepal (Gupta et al., 2000). High genetic diversity has been noted among different foxtail millet accessions of Nepal collected by Nakayama et al. (1999). Amgai et. al., (2011) studied five 
accessions of Nepalese foxtail millet collected from Mugu, Dolpa, Bajhang, Bajura and Lamjung districts of Nepal. They observed a wide range of variability for different agromorphological traits.

Nepalese foxtail millet indigenous germplasms can be classified into tropical group based on Pro2f allele of prolamin. Pro2b allele was rare in the crop (Nakayama et al., 1999). Furthermore, Kawase and Sakamoto (1984) also discovered variation in esterase in Nepalese foxtail millets. Positive phenol coloration was mainly found in accessions collected for the study from Philippines, Taiwan, India, and Nepal (Kawase and Sakamoto, 1982).

There are limited research and handful of publications on this underutilized crop in the country. Thus, this research can act as a pivotal study as an initiation as well as a reference for further researches on foxtail millets. The objective of this study was to evaluate the diversity among foxtail millet accession collected from different parts of Nepal which may help to explore the variability of germplasms available in Nepal, which ultimately contribute in exploitation of genetic makeup of available accessions and characteristics of plants for future breeding research.

\section{Methodology}

Ten foxtail millet (Setaria italica (L.) Beauv.) accessions collected from different parts of Nepal were studied (Fig 1). The seed samples were obtained from National Genetic Resource Centre, Khumaltar, Lalitpur, Nepal. The research plot was laid out in Randomized Complete Block Design (RCBD) with 10 foxtail millet accessions as treatment and three replications. The accessions used in the study are presented in Table 1. The research area was located at $27.642453^{\circ}$ latitude and $84.345760^{\circ}$ longitude with an elevation of 190 masl. The research location is characteristics of subtropical climate. The unit plot size was $1 \mathrm{~m}^{2}$ and had 4 rows of crop sown at a distance of $25 \mathrm{~cm}$ between the rows. Inter block spacing of $1 \mathrm{~m}$ and inter plot spacing of $50 \mathrm{~cm}$ was maintained. Fertilizer application was done at the rate of 30:20:0 kg NPK per ha. The seeds were sown continuous at about $2.5 \mathrm{~cm}$ deep on rows with inter row spacing of $25 \mathrm{~cm}$.

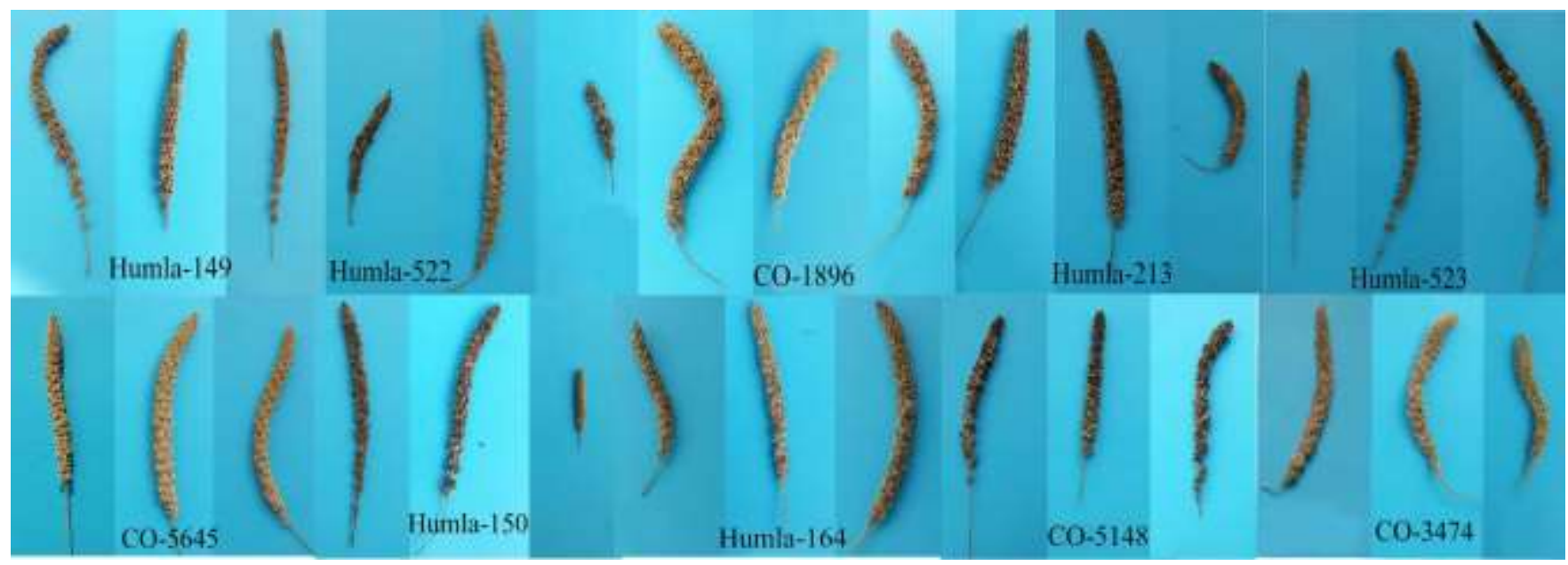

Fig. 1: Diversity in the panicles of foxtail millet accessions under the study

Table 1: Details of 10 foxtail millet accessions included in the study

\begin{tabular}{lllll}
\hline SN & Accession & Local name & District & Altitude (m, asl) \\
\hline 1 & Co-1896 & Kaguno & Jumla & 2,290 \\
2 & Co-3474 & Kaguno & Bajhang & 1,764 \\
3 & Co-5148 & KaloKaguno & Humla & 2,200 \\
4 & Co-5645 & SetoKaguno & Lamjung & 1,800 \\
5 & Humla-149 & RatoKaguno & Humla & 2,300 \\
6 & Humla-150 & KaloKaguno & Humla & 2,300 \\
7 & Humla-164 & PiyaloKaguno & Humla & 2,100 \\
8 & Humla-213 & KaloKaguno & Humla & 2,200 \\
9 & Humla-522 & SetoKaguno & Humla & 2,050 \\
10 & Humla-523 & RatoKaguno & Humla & 2,050 \\
\hline
\end{tabular}




\section{Qualitative Observations}

Characters were evaluated following the foxtail millet descriptor (IBPGR, 1985). First leaf shape: assessed at Zadok's scale 11, seedling anthocyanin coloration of basal leaf sheath: assessed at Zadok's 15, plant anthocyanin coloration of leaf pedestal assessed at Zadok's 35, foliage colour: assessed at Zadok's 35, plant growth habit: assessed at Zadok's 35, leaf altitude of blade: assessed at Zadok's 47, panicle anthocyanin coloration of bristles, anther color: assessed at Zadok's 65, length of bristles: assessed at Zadok's 65, panicle shape: assessed at Zadok's 91 and panicle attitude in relation to stem: assessed at Zadok's 91 were evaluated based on the description given in IBPGR foxtail millet descriptor.

\section{Shannon Weiner index}

The Shannon index has been a popular diversity index, where it is also known as Shannon's diversity index, the Shannon-Wiener index, the Shannon-Weaver index and the Shannon entropy (Spellerberg and Fedor, 2003). It is calculated as follows:

$H^{\prime}=-\sum_{i=1}^{R} p_{i} \ln p_{i}$

Where $p_{i}$ is the proportion of the traits,

i.e. $p_{i}=\frac{\text { population bearing given trait }}{\text { total population }}$

\section{Evenness}

The distribution of traits over the population can be taken as the evenness. Evenness denoted by "J" can be defined as (Peet, 1974):

$J=\frac{H^{\prime}}{\ln (S)}$

Where, $H^{\prime}=$ Shannon Weiner index and $S=$ number of cases

Data entry and processing was carried out using Microsoft Excel 2016 and Microsoft Word 2016 software. Diversity was assessed with the help of MS Excel 2016. The above mentioned indices were calculated from the collected data.

\section{Result and Discussions}

The frequency of appearance of all the traits observed are presented in Table 3. A fair amount of diversity was found in the collected germplasms in which the experiment was carried out. The diversity was assessed with the help of Shannon Wiener index presented in Table 2. The maximum number of diversity in traits of lobe compactness of panicle (1.3624) followed by panicle lodging (1.1595), inflorescence compactness (1.1235) and length of bristles (1.0681). Least diversity was observed in trait of growth habit $(0.3926)$ followed by panicle anthocyanin coloration (0.4505) and lobes in panicles (0.5799). The Shannon Weiner index for other traits can are explained in the Table 2.

Table 2: Shannon Weiner index and Evenness of the traits of foxtail millet accessions under study

\begin{tabular}{lll}
\hline Traits & Shannon Wiener index & $\begin{array}{l}\text { Evenness } \\
(\mathbf{J})\end{array}$ \\
\hline Tip of first leaf & 0.693 & 1.000 \\
Anthocyanin at leaf base & 0.684 & 0.987 \\
Lobe compactness & 1.362 & 0.983 \\
Length of bristles & 1.068 & 0.972 \\
Anthocyanin Presence at Zadoks 15 stage & 0.673 & 0.971 \\
Leaf blade altitude & 1.014 & 0.923 \\
Flag Leaf color & 0.983 & 0.895 \\
Lobe in panicles & 0.580 & 0.837 \\
Panicle lodging & 1.160 & 0.836 \\
Inflorescence compactness & 1.124 & 0.810 \\
Overall color & 0.868 & 0.790 \\
Panicle anthocyanin & 0.451 & 0.650 \\
Panicle shape & 0.639 & 0.582 \\
\hline Growth Habit & 0.393 & 0.567
\end{tabular}


Table 3: Frequency of different traits under study

\begin{tabular}{|c|c|c|c|c|c|}
\hline Traits studied & & Frequency & Percent & $\begin{array}{l}\text { Valid } \\
\text { Percent }\end{array}$ & $\begin{array}{l}\text { Cumulative } \\
\text { Percent }\end{array}$ \\
\hline \multirow[t]{4}{*}{ Tip of first leaf } & Pointed & 15 & 50.0 & 50.0 & 50.0 \\
\hline & Pointed to & 15 & 50.0 & 50.0 & 100.0 \\
\hline & Round & & & & \\
\hline & Total & 30 & 100.0 & 100.0 & \\
\hline \multirow[t]{4}{*}{ Overall color } & Light green & 5 & 16.7 & 16.7 & 16.7 \\
\hline & Medium green & 20 & 66.7 & 66.7 & 83.3 \\
\hline & Dark green & 5 & 16.7 & 16.7 & 100.0 \\
\hline & Total & 30 & 100.0 & 100.0 & \\
\hline \multirow{3}{*}{$\begin{array}{l}\text { Anthocyanin Presence at Zadoks } \\
15 \text { stage }\end{array}$} & Absence & 18 & 60.0 & 60.0 & 60.0 \\
\hline & Presence & 12 & 40.0 & 40.0 & 100.0 \\
\hline & Total & 30 & 100.0 & 100.0 & \\
\hline \multirow[t]{4}{*}{ Growth Habit } & Erect & 26 & 86.7 & 86.7 & 86.7 \\
\hline & Semi erect & 4 & 13.3 & 13.3 & 100.0 \\
\hline & Total & 30 & 100.0 & 100.0 & \\
\hline & Erect & 26 & 86.7 & 86.7 & 86.7 \\
\hline \multirow[t]{3}{*}{ Anthocyanin at leaf base } & Absence & 17 & 56.7 & 56.7 & 56.7 \\
\hline & Presence & 13 & 43.3 & 43.3 & 100.0 \\
\hline & Total & 30 & 100.0 & 100.0 & \\
\hline \multirow[t]{4}{*}{ Leaf blade altitude } & Semi erect & 7 & 23.3 & 23.3 & 23.3 \\
\hline & Horizontal & 16 & 53.3 & 53.3 & 76.7 \\
\hline & Drooping & 7 & 23.3 & 23.3 & 100.0 \\
\hline & Total & 30 & 100.0 & 100.0 & \\
\hline \multirow[t]{4}{*}{ Length of bristles } & Short & 7 & 23.3 & 23.3 & 23.3 \\
\hline & Medium & 10 & 33.3 & 33.3 & 56.7 \\
\hline & Long & 13 & 43.3 & 43.3 & 100.0 \\
\hline & Total & 30 & 100.0 & 100.0 & \\
\hline \multirow[t]{3}{*}{ Panicle anthocyanin } & Absence & 25 & 83.3 & 83.3 & 83.3 \\
\hline & Presence & 5 & 16.7 & 16.7 & 100.0 \\
\hline & Total & 30 & 100.0 & 100.0 & \\
\hline \multirow[t]{4}{*}{ Flag Leaf color } & Light green & 11 & 36.7 & 36.7 & 36.7 \\
\hline & Medium green & 15 & 50.0 & 50.0 & 86.7 \\
\hline & Dark green & 4 & 13.3 & 13.3 & 100.0 \\
\hline & Total & 30 & 100.0 & 100.0 & \\
\hline \multirow[t]{3}{*}{ Lobe in panicles } & Absence & 8 & 26.7 & 26.7 & 26.7 \\
\hline & Presence & 22 & 73.3 & 73.3 & 100.0 \\
\hline & Total & 30 & 100.0 & 100.0 & \\
\hline \multirow[t]{6}{*}{ Lobe compactness } & Loose & 10 & 33.3 & 45.5 & 45.5 \\
\hline & Medium & 6 & 20.0 & 27.3 & 72.7 \\
\hline & Compact & 6 & 20.0 & 27.3 & 100.0 \\
\hline & absent & 8 & 26.7 & & \\
\hline & & & 73.3 & 100.0 & \\
\hline & Total & 30 & 100.0 & & \\
\hline \multirow[t]{4}{*}{ Panicle lodging } & Erect & 6 & 20.0 & 20.0 & 20.0 \\
\hline & Semi erect & 16 & 53.3 & 53.3 & 73.3 \\
\hline & Horizontal & 6 & 20.0 & 20.0 & 93.3 \\
\hline & Drooping & 2 & 6.7 & 6.7 & 100.0 \\
\hline
\end{tabular}


Table 3: Frequency of different traits under study

\begin{tabular}{llllll}
\hline Traits studied & & Frequency & Percent & $\begin{array}{l}\text { Valid } \\
\text { Percent }\end{array}$ & $\begin{array}{l}\text { Cumulative } \\
\text { Percent }\end{array}$ \\
\hline Inflorescence compactness & Total & 30 & 100.0 & 100.0 & \\
& Loose & 3 & 10.0 & 10.0 & 10.0 \\
& Medium & 15 & 50.0 & 50.0 & 60.0 \\
& Compact & 10 & 33.3 & 33.3 & 93.3 \\
& Spongy & 2 & 6.7 & 6.7 & 100.0 \\
\hline Panicle shape & Total & 30 & 100.0 & 100.0 & 10.0 \\
& Conical & 3 & 10.0 & 10.0 & 90.0 \\
& Cylindrical & 24 & 80.0 & 80.0 & 100.0 \\
\hline
\end{tabular}

The evenness of the germplasm of different traits calculated revealed that tip type of first leaf (cotyledonary leaf) was very even $(\mathrm{J}=1)$ followed by anthocyanin pigmentation at leaf base $(\mathrm{J}=0.9871)$ and lobe compactness in panicle $(\mathrm{J}=0.9827)$. The growth habit $(\mathrm{J}=0.5665)$ followed by panicle shape $(\mathrm{J}=0.5816)$ and panicle anthocyanin pigmentation $(\mathrm{J}=0.6500)$ were the least even traits found in the germplasms. The evenness of others traits can be studied from Table 2.

A lot of variation was observed among the ten germplasms used in the experiment. Shannon Wiener diversity index explains the condition of the diversity in the given trait and species. Higher the value of the diversity index, more the diversity present in the trait. Highest diversity was exhibited by the trait panicle lodging (1.159) followed by length of bristles of the panicles (1.0681). This means that the germplasms had shown most diversity in these traits. Growth habit had the least diversity index (0.392), which means that the ten germplasms were least diverse in case of their growth habit. Phenotypic variation of the foxtail millet accessions was related to the diverse geographic origins. Most of studied traits (Table 2) are qualitative and the extensive variability among accessions is probably attributed to the genetic differences as well as the environment in which they were regenerated (Moriss, 2009).

Evenness value gives the equality in the distribution of the traits in the population. Evenness value equal to one means a completely even population i.e. the traits and population are equally distributed. The ten germplasms were highly even in some traits whereas they were observed to have unevenness in the distribution as well. Tip of cotyledonary leaf had evenness of one i.e. the tip leaf type oval and pointed shape were equally distributed among the population. The next trait having higher evenness value was found to be anthocyanin pigmentation at leaf base (0.987). The trait which had least evenness was observed to be growth habit of the germplasms (0.566) which also had the lowest diversity index $(\mathrm{H})$. Higher level of variability can be found in Nepalese foxtail millet. Therefore, Nakayama et al; (1999) concluded that Nepal could be one of the centers of diversity for foxtail millet.

The study of diversity in performance of crops revealed a wide diversity in different qualitative traits and less evenness in the distribution of the traits in the population. Higher level of variability was found in the ten germplasms used in the experiment. Therefore, it could be a beneficial information for the exploration of further genetic diversity.

\section{Acknowledgement}

The authors are highly indebted to Senior Scientist, Krishna Hari Ghimire, National Agriculture Genetic Resource Centre (NAGRC), Khumaltar, Mr. Rajeev Dhakal, Mr. Sandesh Neupane and Mr. Sajal Sthapit, for their constant monitoring and valuable suggestions during the research period. The author would also like to acknowledge LIBIRD for the provision of the fund and economic support for the conduction and success of the research.

\section{References}

Amgai RB, Pantha S, Chhetri TB, Budhathoki SK, Khatiwada SP and Mudwari A (2011) Variation on agro-morphological traits in Nepalese foxtail millet (Setaria italica (L) $\mathrm{P}$ Beauv). Agronomy Journal of Nepal 2: 133-138.

Brink M (2006) PROTA (Plant Resources of Tropical Africa / Ressources végétales de l'Afrique tropicale) (Ed.: M. B. Brink, G. (Editors).), Wageningen, Netherlands.

Fedorov A (1974) Chromosome numbers of flowering plants. Koenigstein, Fed. Rep. Germany, Otto Koeltz Science Publishers.

Gupta SR, Upadhyay MP and Dongol DM (2000) Nepalese accession catalogue 2000. Agriculture Botany Division, NARC, Khumaltar.

Heip CHR, Herman PMJ and K Soetaert (1998) Indices of diversity and evenness. Oceanis, 24(4): 61-87.

HMGN/MFSC (His Majesty's Government of Nepal/Ministry of Forests and Soil Conservation), Nepal (2002) Nepal 
Biodiversity Strategy. Ministry of Forests and Soil Conservation, HMG, Nepal. 117 p.

IBPGR. (1985) Descriptors for Setaria italica and S. pumila. Rome, Italy: IBPGR Secretariat

Kawase M and Sakamoto S (1984) Variation, geographical distribution and genetical analysis of esterase isozymes in foxtail millet, Setaria italica (L.) P. Beauv. Theoretical and Applied Genetics 67 (6): 529-533. DOI: $10.1007 /$ bf00264899

Kawase M. and Sakamoto S (1982) Geographical distribution and genetic analysis of phenol color reaction in foxtail millet, Setaria italica (L.) P. Beauv. Theoretical Applied Genetics 63: 117-119. DOI: 10.1007/BF00303690

Li Y and Wu SZ (1996) Traditional maintenance and multiplication of foxtail millet (Setaria italica(L.) P. Beauv.) landraces in China. Euphytica 87: 33-38. DOI: 10.1007/BF00022961

Lin HS, Liao GI, Chiang CY, Kuoh CS and Chang SB (2012). Genetic diversity in the foxtail millet (Setaria italica) germplasm as determined by agronomic traits and microsatellite markers. American Journal of Crop Science 6(2): 342-349.

Lu H, Zhang J, Liu KB, Wu N, Li Y, Zhou K, Ye M, Zhang T, Zhang H and Yang X (2009) Earliest domestication of common millet (Panicum miliaceum) in East Asia extended to 10,000 years ago. Proc Natl Acad. Sci USA 106(18): 7367-7372. DOI: 10.1073/pnas.0900158106

Marathee JP (1993) Structure and characteristics of the world millet economy. In: Riley KW, Gupta SC, Seetharam A and Mushonga JN (Eds.) Advances in small millets. Oxford and IBH Publ. Co. Pvt. 66 Janapath, New Delhi, India, Pages 159-178.

Ministry of Agricultural Development (MoAD) (2014) Statistical Information on Nepalese Agriculture, Index of major agriculture production, Government of Nepal, Ministry of Agricultural Development (MoAD), Agribusiness Promotion and Statistics Division, Statistical Section, Singha Durbar, Kathmandu, Nepal (http://www.moad.gov.np/ uploads/files/ Year\%20 book\%202014.pdf)

Morris JB (2009). Characterization of sesame (Sesamum indicum L.) accession regenerated in Georgia, USA. Genet Resour Crop Evol, 56: 925-936. DOI: 10.1007/s10722-009-94119

Nakayama H, Namai H and Okuno K (1999) Geographical dis tribution of the alleles at the two prolamin loci, Pro 1 and Pro 2, in foxtail millet, Setaria italica (L.) P. Beauv. Genes Genet. Syst. 74: 293-297. DOI: 10.1266/ggs.74.293

Peet RK (1974) The measurements of species diversity. Ann. Rev. Eeal. System 5: 285-307. DOI: 10.1146/annurev.es.05.110174.001441

Singh B, Bahunga A and Bhatt A (2015) Small millets of Uttarakhand for sustainable nutritional security and biodiversity conservation. International Journal of Management and Social Sciences Research (IJMSSR) 4(8): 2319-4421.

Spellerberg IF and Fedor PJ (2003) A tribute to Claude Shannon (1916-2001) and a plea for more rigorous use of species richness, species diversity and the 'Shannon Wiener' Index. Global Ecology and Biography 12: 177-179. DOI: 10.1046/j.1466-822X.2003.00015.x

Upreti RP (1999) Status of millet genetic resources in Nepal: Wild relatives of cultivated plants in Nepal. Pp. 78-82 in Wild relatives of cultivated plants in Nepal (R. Shrestha and B. Shrestha, eds.). Proceedings of national conference on wild relatives of cultivated plants in Nepal, 2-4 June 1999, Kathmandu. Green Energy Mission/Nepal, Kathmandu, Nepal. 